\title{
TRANSEXUALIDADE E TEORIA DO RECONHECIMENTO: DE UM MODELO \\ PATOLOGIZANTE A UMA NOVA MANEIRA DE PENSAR ATRAVÉS DA CONTRIBUIÇÃO TEÓRICA DE NANCY FRASER
}

\section{TRANSSEXUALITY AND THEORY OF RECOGNITION: A FORM PATHOLOGIZING A NEW WAY TO THINK THROUGH CONTRIBUTION NANCY FRASER THEORY}

\author{
${ }^{1}$ Jessica Cristianetti
}

\section{RESUMO}

As minorias transexuais ainda passam por diversos percalços para terem efetivados seus direitos, serem reconhecidos em igualdade com os demais cidadãos, e para deixarem de ser vistos como doentes. Para tanto, objetiva-se neste estudo entender como é possível pensar em um modelo despatologizante de tratar a transexualidade, para isto, utiliza-se da teoria do Reconhecimento de Axel Honneth e Nancy Fraser, com a finalidade de compreender qual melhor se adéqua a questão da inclusão de minorias não hegemônicas no processo deliberativo majoritário, a fim de corrigir os desvios do procedimento democrático e com a pretensão de concretizar a paridade de participação e desconstruir a ideia de patologia envolvendo o transexualismo.

Palavras-chave: Estigmatização, Minorias, Reconhecimento, Transexualidade

\begin{abstract}
The Transsexuals minorities still pass through many mishaps to have effected their rights be recognized on equal terms with other citizens, and are no longer seen as patients. Therefore, the objective of this study was to understand how you can think of a despatologizante model of treating transsexuality, for this, we use the theory of recognition Axel Honneth and Nancy Fraser, in order to understand which one best fits the question the inclusion of nonhegemonic minorities in majority decision-making process in order to put the derailed democratic procedure and with the intention of achieving parity of participation and deconstruct the idea of pathology involving transsexualism.
\end{abstract}

Keywords: Stigmatization, Minorities, Recognition, Transsexuality

\footnotetext{
${ }^{1}$ Mestrado em Direito pela Universidade do Vale do Rio dos Sinos (UNISINOS), Rio Grande do Sul (Brasil). E-mail: jessicacristianetti@ hotmail.com
} 


\section{INTRODUÇÃO}

No presente trabalho estudar-se-á as questões atinentes aos direitos das minorias transexuais, como, por exemplo, a CID-10 que regula o funcionamento de todo o processo da mudança de sexo até a cirurgia de redesignação, e para tanto, traz requisitos a serem respeitados, bem como é aquela que caracteriza como patológica a transexualidade, entre demais disposições. Ainda, estudar-se-á o Projeto de Lei no 5.002/2013, pelo motivo de ser este o que parece o mais adequado, já que muda a concepção de que transexualidade é uma doença de desvio mental e comportamental, bem como regula de forma mais facilitada o processo de mudança de sexo e de prenome, inclusive para menores de idade, o que dá esperanças de um futuro melhor para os afetados.

Ademais, buscar-se-á compreender as principais bases teóricas da teoria filosófica do reconhecimento de Axel Honneth e de Nancy Fraser, com o objetivo de compreender como estas teorias podem auxiliar nas questões acerca do reconhecimento, despatologização e inclusão de minorias trans em um ambiente hostil como o vivenciado.

Depois de estudadas as principais questões atinentes à transexualidade e à teoria do reconhecimento, pretende-se ligar estes pontos na busca de uma visão despatologizante do discurso colocado, bem como analisar qual autor aborda sua teoria de forma mais satisfatória a concretizar a inserção deste grupo minoritário na sociedade, e que possa ainda, garantir a igualdade destes com os demais grupos da sociedade. Se o ideal é a concepção de reconhecimento como autorrealização, de Honneth, ou o entendimento de reconhecimento como uma forma justiça, defendido por Fraser.

\section{CONSIDERAÇÕES ACERCA DA TRANSEXUALIDADE}

Neste primeiro momento, abarcam-se as principais considerações acerca da transexualidade para que seja possível o desenrolar do presente estudo. Para tanto, primeiramente, se faz relevante impor as diferenças conceituais acerca de travestis, homossexuais, intersexuais e o transexual em questão.

Assim sendo: 


\begin{abstract}
As pessoas transexuais são diferenciadas das pessoas homossexuais, que têm apenas uma orientação sexual dirigida para o mesmo sexo, e não uma insatisfação com o seu sexo; e dos travestis, que se expressam, vestindo-se e comportando-se como pertencente ao sexo oposto ao seu, mas não acreditam necessariamente possuir uma corporeidade equivocada; e das pessoas intersexuais, que possuem características de ambos os sexos decorrentes de algum tipo de distúrbio ou anomalia de base orgânica, como os hermafroditas. (VENTURA, 2007, P. 148-149)
\end{abstract}

O transexual é aquela pessoa aprisionada em um corpo que não reconhece como seu, é o homem que se vê e se entende, psiquicamente, como mulher, mas no corpo de um homem e assim, expressa claramente seu desejo de mudar para o sexo oposto, através de cirurgia realizada para tanto.

Através da CID-10 $10^{1}$ entende-se a transexualidade como um transtorno mental e de comportamento, ou seja, é vista como uma doença. E por ser assim, é necessário percorrer um longo caminho até chegar à cirurgia de mudança de sexo. O Conselho Federal de Medicina, através da Resolução CFM n 1.955 de 2010 regula todo este processo e assim sendo, diagnostica um transexual com base em algumas características, consoante o que dispõe o art. $3^{\circ}:$
Art. $3^{\circ}$ Que a definição de transexualismo obedecerá, no mínimo, aos critérios abaixo enumerados:
1) Desconforto com o sexo anatômico natural;
2) Desejo expresso de eliminar os genitais, perder as características primárias e secundárias do próprio sexo e ganhar as do sexo oposto;
3) Permanência desses distúrbios de forma contínua e consistente por, no mínimo, dois anos;
4) Ausência de outros transtornos mentais. (Onde se lê "Ausência de outros transtornos mentais", leia-se "Ausência de transtornos mentais")

Ainda, traz disposição de como funcionará o processo até a realização da cirurgia de transgenitalização:
Art. $4^{\circ}$ Que a seleção dos pacientes para cirurgia de transgenitalismo obedecerá a avaliação de equipe multidisciplinar constituída por médico psiquiatra, cirurgião, endocrinologista, psicólogo e assistente social, obedecendo os critérios a seguir definidos, após, no mínimo, dois anos de acompanhamento conjunto:
1) Diagnóstico médico de transgenitalismo;
2) Maior de 21 (vinte e um) anos;
3) Ausência de características físicas inapropriadas para a cirurgia.

Analisando-se este dispositivo da Regulamentação, contata-se o longo período percorrido até a cirurgia de transgenitalismo. O que pretende-se analisar neste trabalho é como funciona o estigma carregado pelo transexual neste longo processo onde este é avaliado por diversos profissionais, passa por diversas consultas, tendo sempre que afirmar sua vontade

\footnotetext{
${ }^{1}$ Código Internacional de Doenças
} 
de mudar o sexo biológico, são dois anos de avaliação que por vezes acabam por gerar mais opressão e estigma à esta pessoa.

Por muito tempo considerou-se que a cirurgia de mudança de sexo tinha caráter mutilante e não corretivo, assim, o médico que realizasse tal procedimento cometia crime de lesão corporal grave, a partir da primeira Resolução do Conselho Federal de Medicina (n ${ }^{\circ}$ 1.482) em 1997 tal ato deixou de ser criminalizado, posteriormente foi editada a Resolução 1.652 de 2002, sendo revogada pela atual Resolução no 1.955 de 2010. (BUNCHAFT, 2014, P. 51) No ano de 2008 foram oficializadas as cirurgias de redesignação sexual pelo Governo Brasileiro.

Acerca da patologização em torno do transexualidade, Bunchaft (2014, p. 52) assevera que,

[...] é mister considerar que os efeitos estigmatizantes da medicalização e patologização decorrentes dos discursos biomédicos sobre transexualidade terminam por fazer com que as pessoas transexuais construam suas autoimagens como sendo de pessoas doentes e afetadas por um transtorno de identidade de gênero.

Portanto, a cirurgia pode ser vista como potencializadora do estigma e da exclusão social, trazendo mais danos ainda à psique do transexual. Pois assim como a cirurgia é a promessa de uma nova vida ela também é um caminho tortuoso para quem a enfrenta. Nesta senda,

Em suma: a abordagem patologizante tem sido criticada porque: a) reforça concepções estereotipadas de uma divisão binária de gênero situada fora da história; b) estigmatiza pessoas transgêneras como doentes ou anormais; c) é subinclusiva porque exclui quem não se encaixa nos estereótipos culturais de masculinidade e feminilidade exigidos para a transformação corporal; d) atribui ao profissional da medicina a função de anteparo ao exercício de diversos direitos, tais como o casamento e a retificação do registro civil, na medida em que, quando tais direitos são legalmente reconhecidos, cirurgias reconstrutivas e pareceres médicos são exigidos para que os órgãos públicos garantam o exercício efetivo do direito buscado. (SUIAMA, 2011, p. 177)

No tocante às posições defendidas, Bunchaft (2014, p. 53) assevera que, "alguns consideram o diagnóstico como uma condição que garante a realização da cirurgia no serviço e os que defendem a exclusão da necessidade de diagnóstico, pois os transexuais teriam direito a disposição do próprio corpo".

Ou seja, uma parcela crê que mesmo podendo ser estigmatizante o processo até o diagnóstico, ele é válido, já que leva até a cirurgia de mudança de sexo que mudará a vida do transexual. Por outro lado, alguns entendem que não seria necessário todo este processo até o diagnóstico e se baseiam, para tanto, na ideia de que o transexual sabe o que é melhor para seu corpo, até porque muitas vezes eles mesmos já se reconhecem como tal desde a mais tenra 
idade e assim, o fato de ter que passar por tal percurso até o diagnóstico só serviria para oprimir e estigmatizar mais ainda esta classe minoritária.

Para Suiama (2011, p. 168), “o reconhecimento de que transgêneros têm, nessas condições, direitos de personalidade representa um progresso em relação a posturas conservadoras que simplesmente negam qualquer realidade de gênero para além da genética".

Concorda-se com o autor, que possui visão otimista acerca da situação, porém, neste momento, tendo reconhecidos estes direitos necessita-se lutar para a plena efetivação destes, para que possam ser efetivados sem o caráter estigmatizante e opressor que os impregna, já que esta "minoria da minoria" já foi por muito tempo renegada de seus direitos mais essenciais: a mudança de sexo e a mudança do nome.

Jean Wyllys, e Érika Kokay, ambos deputados, possuem um Projeto de Lei chamado “Lei João W. Nery", sob nº 5.002/2013, este PL versa sobre a identidade de gênero, traz questões inovadoras com o viés de abandonar o estigma de que o transexualidade seria um transtorno mental e de comportamento, abrindo caminho até mesmo para menores de 18 anos que queiram realizar a cirurgia ou a mudança do nome, mas nestes casos existem alguns requisitos a serem seguidos.

$\mathrm{Na}$ justificativa de tal projeto de lei, os deputados expõem diversos pontos para entender a importância de tal projeto, cola-se aqui passagem que exprime esta relevância:

Falamos de pessoas que se sentem, vivem, se comportam e são percebidas pelos outros como homens ou como mulheres, mas cuja identidade de gênero é negada pelo Estado, que reserva para si a exclusiva autoridade de determinar os limites exatos entre a masculinidade e a feminidade e os critérios para decidir quem fica de um lado e quem do outro, como se isso fosse possível. Travestis, transexuais e transgêneros sofrem cada dia o absurdo da lei que lhes nega o direito a ser quem são. $\left(\mathrm{PL} \mathrm{n}{ }^{\circ} 5.002,2013\right.$, p. 7)

Vejamos alguns dos pontos principais deste PL ( $\left.n^{\circ} 5.002,2013\right)$ :

Artigo $8^{\mathbf{0}}$ - Toda pessoa maior de dezoito (18) anos poderá realizar intervenções cirúrgicas totais ou parciais de transexualização, inclusive as de modificação genital, e/ou tratamentos hormonais integrais, a fim de adequar seu corpo à sua identidade de gênero auto-percebida. $\$ \mathbf{1}^{\circ} \mathbf{E m}$ todos os casos, será requerido apenas o consentimento informado da pessoa adulta e capaz. Não será necessário, em nenhum caso, qualquer tipo de diagnóstico ou tratamento psicológico ou psiquiátrico, ou autorização judicial ou administrativa. $\$ 2^{\circ}$ No caso das pessoas que ainda não tenham de dezoito (18) anos de idade, vigorarão os mesmos requisitos estabelecidos no artigo $5^{\circ}$ para a obtenção do consentimento informado. (grifos meus)

\footnotetext{
${ }^{2}$ A última ação legislativa deste projeto foi a designação do Relator Dep. Luiz Couto (PT/PB) na Comissão de Direitos Humanos e Minorias, na data de 26 de Maio de 2015. Atualmente está aguardando Parecer do citado Relator. Disponível em: <http://www.camara.gov.br/proposicoesWeb/fichadetramitacao?idProposicao=565315>. Acessado em 10 de Agosto de 2015.
} 
Ou seja, a partir da ideia deste PL, apenas o consentimento informado já seria o bastante para a possibilidade da realização da cirurgia de transgenitalização, não haveria nenhum processo de diagnóstico, já que tal questão não seria uma doença, isto cabe para os maiores de idade, já no caso dos menores:

\begin{abstract}
Artigo $5^{\mathbf{0}}$ - Com relação às pessoas que ainda não tenham dezoito (18) anos de idade, a solicitação do trâmite a que se refere o artigo $4^{\circ}$ deverá ser efetuada através de seus representantes legais e com a expressa conformidade de vontade da criança ou adolescente, levando em consideração os princípios de capacidade progressiva e interesse superior da criança, de acordo com o Estatuto da Criança e do Adolescente. $\$ \mathbf{1}^{\circ}$ Quando, por qualquer razão, seja negado ou não seja possível obter o consentimento de algum/a dos/as representante/s do Adolescente, ele poderá recorrer ele poderá recorrer a assistência da Defensoria Pública para autorização judicial, mediante procedimento sumaríssimo que deve levar em consideração os princípios de capacidade progressiva e interesse superior da criança. $\$ 2^{\mathbf{0}} \mathbf{E m}$ todos os casos, a pessoa que ainda não tenha 18 anos deverá contar com a assistência da Defensoria Pública, de acordo com o estabelecido pelo Estatuto da Criança e do Adolescente.
\end{abstract}

Vê-se que não é um processo indiscriminado de realizar a cirurgia, já que existem requisitos importantes a ser observados, esta questão surge pelo motivo de que a maioria dos transexuais já se compreenderem como tais desde muito jovens. Aguardar até que atinjam a maioridade, por vezes, acaba sendo um processo de maior estigma, exclusão e opressão social. Assim, este PL visa garantir os direitos dos menores que queiram se submeter a cirurgia de transgenitalização e/ou a mudança do prenome.

Acerca da mudança do prenome, até o ano de 1990 o entendimento jurisprudencial majoritário era de que o nome era imutável e que a cirurgia de mudança de sexo não era fator para a mudança no prenome, pois o sexo não era uma escolha e sim uma imposição biológica. A partir do ano supracitado, o Tribunal de Justiça do Rio Grande do Sul passou a decidir favoravelmente à possibilidade da mudança do prenome no registro do transexual redesignado, porém estas decisões começaram a se basear no vexame que passariam os transexuais com um nome não correspondente ao seu corpo e assim, acabou-se por relativizar a problemática. (BUNCHAFT, 2014)

A decisão do STJ em 2009 selou o entendimento de que a mudança do prenome é possível após a cirurgia de redesignação (BUNCHAFT, 2014, p. 57), o que traz sérios transtornos para aqueles que ainda não chegaram à tal cirurgia. Por este motivo, se faz de grande importância o Projeto de Lei dos deputados Jean Wyllys e Érika Kokay, pois este regulamenta estas questões da forma mais sensível aos anseios dos principais afetados, qual seja

as minorias

trans. 
É mister frisar que diversos direitos ainda não são assegurados aos transexuais, como o direito de adoção, acesso à saúde, casamento, retificação do prenome, entre outros.

Agora, portanto, inicia-se outra discussão desencadeada pelos motivos já expostos: como regulamentar estas questões ainda abertas sem uma posição legislativa definitiva? Qual postura exercer até que o Congresso resolva pôr em votação algum projeto acerca dos direitos dos transexuais? A intervenção judicial se faz legitima neste âmbito?

Para tanto, na próxima parte do trabalho, analisar-se-á as questões atinentes às minorias trans com base na Teoria Filosófica do Reconhecimento, a fim de compreender se esta discussão refere-se a uma questão de justiça ou de autorrealização e como é tratada pelos autores da teoria referida.

\section{A TEORIA DO RECONHECIMENTO DE AXEL HONNETH E NANCY FRASER}

Nesta parte do trabalho apresentar-se-á as bases teóricas da Filosofia do Reconhecimento, tendo como os autores base, Axel Honneth e Nancy Fraser que trabalham esta teoria por vias distintas.

Hegel é a grande inspiração da teoria do Reconhecimento para Honneth, e ainda, este último baseia-se nos aporte da teoria de Herbert Mead, que é a psicologia social.

A teoria desenvolvida por Honneth, consoante Patrícia de Mattos, objetiva "construir uma teoria crítica do reconhecimento que permita pensar em caminhos emancipatórios a partir do não reconhecimento". (MATTOS, 2006, P. 95)

Honneth apenas traz em sua pesquisa uma esfera, qual seja, o âmbito do Reconhecimento, pois para o filósofo "todos os conflitos sociais tem como natureza primária a luta por reconhecimento" (MATTOS, 2006, P. 147), assim compreende que sempre existe em um conflito primariamente a busca pelo reconhecimento. Nancy Fraser, diferentemente, trabalha em sua teoria do Reconhecimento com três esferas do conflito, sendo estas: a esfera do Reconhecimento que se traduziria em status social: a dimensão cultural; e a esfera da Redistribuição, onde se abarca os conflitos de classe social: a dimensão econômica e a Representação: relativa ao plano político.

Considera-se estas esferas como pontos conexos que não podem ser separados jamais, já que para a efetivação da justiça social é preciso ambas as dimensões, desta forma, 
haveria entre estas esferas uma imbricação que as torna inseparáveis em qualquer tipo de movimento social.

Tem-se aqui um primeiro de muitos desacordos teóricos entre os teóricos do reconhecimento.

A socióloga considera a justiça social como um caso de representação e de reconhecimento também, e não apenas de redistribuição "ela acredita que a injustiça econômica está ligada à injustiça cultural e vice-versa” (MATTOS, 2006, P. 144).

Para exemplificar esta questão, tem-se o exemplo da identidade de gênero, que seria uma "categoria tridimensional situada na estrutura econômica, na ordem de status e na esfera da representação. Assim, os transexuais, no Brasil, estariam submetidos" às três esferas de Fraser, sendo que estas estão mutuamente imbricadas.

Esta ideia de que redistribuição, reconhecimento e representação estão sempre juntos, mesmo que de forma indireta, é o que Fraser chama de perspectiva tridimensional.

De forma contrária, Axel Honneth entende que as duas esferas (reconhecimento e redistribuição), não se complementam, pois em sua concepção, a raiz de todo conflito, sempre, estará vinculada a uma reivindicação por reconhecimento. No que concerne à divisão realizada por Fraser (lutas por redistribuição e lutas por reconhecimento cultural), o filósofo explicita que "essa dicotomia entre as lutas suprime ou negligencia as lutas por reconhecimento presentes em todos os conflitos por igualdade igual” (MATTOS, 2006, P. 155), já que em sua concepção é imprescindível a existência de uma análise da gramática moral que estaria atrás de todos os conflitos sociais vivenciados.

Existem três formas de reconhecimento para Honneth: o amor, o direito e a estima, estas três formas de reconhecimento correspondem a três formas de desrespeito, o que, neste caso, pode ser um fator para o desencadeamento de conflitos sociais.

O amor, que seria a primeira esfera do reconhecimento, é aquele sentimento de afeto que a criança desenvolve na infância, assim, é papel dos pais o auxilio para com seus filhos no desenvolvimento da autoconfiança, após esta fase inicial da infância, o afeto mútuo aparece através do casamento. Entretanto, o reconhecimento dos cidadãos como sujeitos de direito é a esfera mais relevante, assim, todos são iguais perante a sociedade. Aquilo que diferencia você dos demais sujeitos corresponde à estima social, e esta diferenciação ocorre por meio da divisão do trabalho. (FRASER; HONNETH, 2003b) 
No tocante às formas de desrespeito correspondentes às formas de reconhecimento supracitadas, tem-se, a tortura, onde advém o não reconhecimento da autonomia do sujeito sobre o seu próprio corpo, a segunda seria o não reconhecimento no âmbito do direito, já que este abala o autorrespeito, exemplificando-se: o não reconhecimento do direito ao casamento civil entre pessoas do mesmo sexo pela concepção de que não são dignos de tal reconhecimento. (MATTOS, 2006, P. 96) Pode-se utilizar como outro exemplo para tanto, a questão de não se reconhecer os direitos à mudança do prenome do transexual com a mesma desculpa dado no caso do casamento homossexual: a indignidade para isto.

A principal divergência deste tópico é a questão de que Honneth trabalha com uma concepção de reconhecimento como voltado à sociologia e à psicologia moral, juntamente, à ideia de que o reconhecimento está imbricado com a autorrealização individual, contrariamente, Fraser não tem essa visão acerca do reconhecimento, para a socióloga, o reconhecimento é uma questão basicamente de justiça, portanto, ela não trabalha em uma perspectiva do não reconhecimento como uma fator de impedimento para a autorrealização, e sim, considera o não-reconhecimento menos em relação às atitudes depreciatórias sofridas pelos sujeitos, entretanto, mais pelo exame de práticas discriminatórias institucionalizadas. (MATTOS, 2006, P. 148)

Acerca da questão do não reconhecimento, para Fraser, "em cada caso, o efeito é a criação de uma classe de pessoas desvalorizadas que se veem impedidos de participar como um par com os outros na vida social. Em cada caso, acordadamente, existe um pedido de reconhecimento" (FRASER; HONNETH, 2003, p. 30). Assim, quando o direito de ser reconhecido em suas especificidades e de possuírem os direitos de participação em igualdade de condições com os demais é negado a algum grupo, estes grupos excluídos passam a reivindicarem seus direitos de inclusão nesta sociedade, essencialmente, de reconhecimento de seus direitos.

A perspectiva de Nancy Fraser no tocante ao reconhecimento é mais aceitável em uma sociedade moderna como a nossa, tendo em conta a marca do pluralismo. Nesta senda, a teoria do reconhecimento de Honneth acaba por ser menos importante, portanto, relegada a um plano secundário.

O objetivo de Fraser é desenvolver neste parâmetro de justiça o conceito de participação paritária, ou seja, a possibilidade de participação equânime de todos os indivíduos no cotidiano e na esfera pública, sem negar esta participação a ninguém por pretexto de não reconhecimento, porquanto isto significaria um ato de violação à justiça. 
Entretanto, para chegar-se a tal ideal de participação paritária se faz imperioso realizar dois aspectos que Fraser (FRASER; HONNETH, 2003, p. 36) esclarece na seguinte passagem:

A distribuição de recursos materiais deve ser de molde a garantir a independência e a "voz" dos participantes. Este chamarei a condição objetiva de paridade participativa. A segunda condição requer que padrões institucionalizados de valor cultural exprimam igual respeito por todos os participantes e garantam a igualdade de oportunidade para alcançar a estima social. Este chamarei a condição intersubjetiva da paridade participativa.

Tais condições tendo sido satisfeitas podemos caminhar para a concretização da participação paritária, esta consiste em uma visão ampliada da visão tradicional de justiça, pelo fato de que são trazidas para seu campo questões objetivas e subjetivas, consoante supracitado.

Estas foram os principais aspectos da teoria do reconhecimento na concepção de Axel Honneth e Nancy Fraser, agora, na próxima parte deste trabalho, analisar-se-á a concepção de contrapúblicos subalternos de Fraser a luz da problemática patologizante que envolve os transexuais.

\section{OS DESAFIOS DA DESPATOLOGIZAÇÃO À LUZ DA TEORIA DO RECONHECIMENTO: OS CONTRAPÚBLICOS SUBALTERNOS DE FRASER}

Interessante esclarecer que se dividem as opiniões acerca da despatologização, já que é o caráter de doença que proporciona às pessoas trans o procedimento de mudança de sexo pelo SUS (sistema único de saúde), de forma gratuita, e, portanto, muitos entendem que por este motivo se justifica caracterizar a transexualidade como patologia. Porém, neste aspecto, o trabalho aqui presente se pretende a analisar a problemática em torno de uma possibilidade de se pensar a transexualidade não como uma patologia, e buscar aspectos que sejam possíveis de levar esta questão a uma despatologização, mas sem adentrar nesta temática da cirurgia gratuita pelo SUS, este ponto de discussão será analisado em etapa posterior à este primeiro trabalho.

Assim, adentra-se na temática proposta por Fraser para auxiliar neste desafio da despatologização da transexualidade. Esta desenvolve a ideia de contrapúblicos subalternos, assim, conceitua como sendo "arenas discursivas paralelas nas quais os membros dos grupos socialmente subordinados inventam e circulam contradiscursos para formular interpretações opostas de suas identidades, interesses e necessidades." (FRASER, 1992, p. 123). 
Na concepção de Bunchaft (2014, p. 72), para Fraser, os contrapúblicos de resistência permitem aos movimentos sociais expandirem a gama de conhecimento de injustiças publicamente articuladas, expandindo o universo da razão pública por meio de formas críticas de comunicação expressas em termos de "contrapúblicos".

Estes contrapúblicos são fatores que enriquecem muito a contenda, já que são diversas arenas de discussão, uma pluralidade de públicos, que assim potencializam a promoção do ideal de paridade de participação, ou seja, são públicos que divergem em condutas e opiniões acerca de determinadas questões que lhe são postas e acabam por enriquecer o debate.

Acerca da concepção do binarismo (homem-mulher ou homo-hétero, como exemplos), esta precisa ser desconstruída com a finalidade de desestabilizar as identidades sexuais, isto seria possível através da constatação de certos públicos alternativos que causam a circulação de discursos de oposição de classes excluídas da esfera pública oficial, como exemplos temos os travestis e os transexuais, o foco deste trabalho. (BUNCHAFT, 2014, p.

73)

Os transexuais podem ser vistos como uma "minoria da minoria", pois grupos de gays e lésbicas por vezes não aceitam pessoas transexuais, conforme corrobora Bunchaft $(2014$, p. 73$)$ ao afirmar que "os transexuais e travestis são minorias sexuais não-hegemônicas cujas demandas e direitos, muitas vezes, são desconsiderados dentro do próprio movimento LGBT".

Em face dessa leitura, a circulação de discursos de oposição de minorias sexuais não hegemônicas excluídas da esfera pública oficial, como os transexuais e travestis, têm paulatinamente potencializado o princípio da paridade de participação delineado por Fraser, minimizando o déficit de liderança política de tais grupos. (BUNCHAFT,

2014, p. 73-

74)

Com esta passagem, entende-se como os discursos realizados por meio da ideia de contrapúblicos subalternos de Nancy Fraser têm o condão de dar voz a uma minoria não hegemônica e assim, contribuir para a efetivação do ideal de paridade de participação na esfera pública.

Bunchaft (2014, p. 74) assevera que está ocorrendo um amadurecimento político no movimento e ressalva a importância de organizações que ultrapassam a fronteira nacional neste processo. Este amadurecimento seria o reflexo na proposta publicada pela $\mathrm{OMS}^{3}$ na versão da CID11, pois esta contempla novas categorias que o Grupo de Trabalho da OMS reivindicava, como a incongruência de gênero na adolescência e idade adulta, e incongruência de gênero na infância. Estas novas categorias passariam a integrar um novo capítulo, este que

\footnotetext{
3 Organização Mundial da Saúde
} 
trata de condições relacionadas com a saúde sexual, a questão mais louvável desta edição da CID é que este capítulo é separado daquele que trata dos transtornos mentais e de comportamento.

Assim, a questão da transexualidade deixaria, a princípio, de ser uma patologia, o que levaria ao fim do caráter estigmatizante atribuído a ela. Entretanto é necessário “analisar e debater sobre a questão de a categoria "incongruência" poder repatologizar as questões trans". (BUNCHAFT, 2014, p. 74)

Mesmo que a intenção seja a mais nobre, é necessário avaliar esta nova categoria atribuída às questões trans, pois pode-se acabar por mudar o nome da categoria, mas na prática nada vir a mudar. Outra questão que se coloca neste ponto é que se a transexualidade deixar de ser uma doença, seria legitimo ainda ser custeada pelo Sistema Único de Saúde? A doutrina majoritária entende que não, pois o atendimento pelo SUS é condicionado à doença, ou seja, este seria um fator a ser amplamente debatido, pois mesmo sendo estigmatizante ter um transexual como doente é esta visão opressora que lhe garante a mudança de sexo sem custo algum. Esta discussão não será difundida nesta pesquisa, por não ser o objetivo principal.

O GATE (Ação Global pela Igualdade Trans) e a STP (campanha internacional Stop Trans Pathologization) “defendem que o acesso à saúde e o reconhecimento da identidade de gênero são direitos humanos e que seu cumprimento não deve depender de categorias diagnósticas" (BUNCHAFT, 2014, P. 74).

Novamente sobre a concepção binária de gênero:

\footnotetext{
Defendemos que a desconstrução discursiva da concepção binária de gênero e a superação da interpretação patologizante, no que se refere à moldura adequada de justiça, devem, à luz do referencial teórico de Fraser, satisfazer a dimensão da representação e contar com o assentimento de todos os concernidos a um processo de deliberação justo e aberto. (BUNCHAFT, 2014, p. 78)
}

Ou seja, tendo como base os estudos sociológicos de Fraser, podemos pensar em uma nova forma de tratar a questão da transexualidade hoje, para tanto, tem-se que superar a concepção do binarismo e o modelo patologizante, assim se poderia assegurar às minorias trans o devido reconhecimento e, por consequência, a paridade de participação nos processo de deliberação, o que o tornaria mais justo.

Outro ponto do diálogo Honneth-Fraser que auxilia na problemática em torno das questões transexuais é a consideração de que transexualidade não deve ser analisada sob o ponto de vista do dano psicológico, do sofrimento, concepção defendida por Honneth, já que 
este se baseia no paradigma da autorrealização pessoal. Portanto, Bunchaft (2014, p. 79) assevera que lutas por reconhecimento com vistas à concretização de direitos de transexuais não podem estar ligadas à concepção de Honneth em torno do sofrimento vivenciado pelo sujeito afetado, já que a ampliação dos processos intersubjetivos por reconhecimento recíproco pode concretizar-se inteiramente através da ideia de paridade de participação que Fraser defende.

A seguinte passagem é elucidativa:

[...] o modelo de status delineado por Fraser, em 2003, pretendia desvincular-se da perspectiva identitária que havia sido delineado por Honneth (2003b), porquanto este, ao enfatizar a dimensão psicológica do reconhecimento, terminava por negligenciar as estruturas sociais, institucionalizadas que impediam a paridade de participação de grupos minoritários. A questão fundamental, portanto, não é focalizar o potencial das experiências de sofrimento, como pretendia Honneth (2003), mas as efetivas implicações das relações raciais assimétricas na esfera da interação social. (BUNCHAFT, 2014, p. 81)

É por este motivo que se defende que a problemática transexual deve ser desvinculada de uma questão de autorrealização, já que são mais concretas quando direcionadas ao ideal de paridade de participação, assim surge a importância da concepção de contrapúblicos subalternos, já que através deste potencializa-se a desconstrução do binarismo e desestabiliza todas as identidades sexuais. Neste âmbito é onde ocorre a discussão de temáticas relativas à realidade dos transexuais, e como consequência, pode-se diminuir a intensa condição de desvantagem que estas minorias sofrem na esfera pública oficial. (BUNCHAFT, 2014, p. 81)

Assim sendo,

[...] a concepção de contrapúblicos subalternos possibilita ao movimento transexual desconstruir concepção binária de gênero do ocidente, o alinhamento automático entre sexo anatômico e identidade sexual e a interpretação patologizante da transexualidade.(BUNCHAFT, 2014, P. 81)

Ou seja, a autorrealização não é o caminho mais adequado para efetivar-se direitos de minorias sexuais que são excluídas do processo político majoritário, já que apenas se baseia na visão psicologizante do dano, a fundamentação para casos como os de transexuais (minorias não hegemônicas) deve ser a questão da paridade de participação no processo deliberativo, já que são negados deste até o momento em que haja o devido reconhecimento de sua classe.

Pelos motivos aqui já expostos compreende-se que a teoria do Reconhecimento como formulada por Fraser, atende na melhor forma questões de exclusão do processo deliberativo e dá uma visão de como podemos tratar o tema da transexualidade em tempos modernos, a

fim de assegurar a estes iguais condições de participação no processo democrático, 
desconstruindo a ideia de "minorias das minorias".

\section{CONCLUSÃO}

Após realizado o presente estudo, tem-se que as minorias trans ainda irão precisar percorrer um longo caminho até que tenham seus direitos mais básicos garantidos. Apesar de a cirurgia de redesignação sexual ser possível, esta vêm com uma carga estigmatizante e opressora, já que trata-se a transexualidade como um transtorno mental e de comportamento, sem tocar no assunto acerca da dificuldade de conseguir a mudança do prenome sem que a cirurgia referida tenha sido realizada.

Ademais, o processo pelo qual o transexual precisa passar para chegar à cirurgia é longo, e por muitas vezes, desgastante, o que leva muitos a desistir no meio do caminho e partirem para outro caminho, como as cirurgias no exterior. Devemos garantir estes direitos com mais facilidade, já que a questão trans não é compatível com a descrição de uma patologia.

Esta visão da transexualidade como doença precisa ser reavaliada, para tanto, tem-se projetos de lei com esta finalidade tramitando, bem como a esperada votação da CID-11, que ocorrerá no ano de 2017, já que esta abandona o foco patologizante e cria nova categoria para tratar das questões trans.

Aplicando-se esta problemática à Teoria do Reconhecimento, conclui-se após o estudo, que a socióloga Nancy Fraser é a que melhor resolve a questão da desconstrução da patologização da transexualidade, bem como, através da concepção dos contrapúblicos subalternos, desconstrói a perspectiva binária homo-hétero e, desestabiliza todas as identidades sexuais trazendo à tona minorias não hegemônicas como os transexuais e fortalecendo-as, principalmente no âmbito da esfera pública. Ou seja, a perspectiva de Fraser traz elementos para repensar como a transexualidade é tratada hoje e como pode ser vista em um futuro próximo, de forma mais justa, sem estigma ou opressão social, bem como, de forma a entender todos como iguais na esfera do processo deliberativo.

O instrumental de Fraser se sobrepõe ao de Honneth no ponto em que resolve a questão do não reconhecimento dos transexuais pela perspectiva da paridade de participação,

já que esta os coloca em par de igualdade com os demais indivíduos no processo de deliberação democrática, onde passam a ter voz por meio destas questões e podem reivindicar suas pretensões.

Por todas as questões abordadas chega-se a está conclusão, Nancy Fraser, teoricamente, trabalha de forma mais congruente a problemática trans ao abordar esta como 
uma questão de justiça e não simplesmente de autorrealização social, como quer Axel Honneth. 


\section{REFERÊNCIAS \\ BIBLIOGRÁFICAS}

BUNCHAFT, Maria Eugenia. Ativismo Judicial e Grupos Estigmatizados:

Filosofia

Constitucional do Reconhecimento. Curitiba: Jurúa,

2014.

FRASER, Nancy; HONNETH, Axel. Redistribution or recognition? - A Political

Philosophical Exchange. London: Verso,

2003a.

FRASER, Nancy. Distorted Beyound all Recognition: A Rejoinder to Axel Honneth. In: FRASER, Nancy; HONNETH, Axel. Redistribution or Recognition?-A Political Philosophical Exchange. London: Verso, 2003.

FRASER, Nancy. Justice Social in the Age of Identity Politics. In: FRASER, Nancy; HONNETH, Axel. Redistribution or Recognition?-A Political Philosophical Exchange. London: Verso, 2003.

MATTOS, Patrícia. A sociologia política do reconhecimento. São Paulo: Annablume, 2006. PL 5.002/2013. Disponível em: http://jeanwyllys.com.br/wp/projetos-de-lei. Acessado em 6 de Agosto

SUIAMA, Sergio Gardenghi. Em busca de um modelo autodeterminativo para o Direito de transgêneros. IN: RIOS, Roger Raupp; GOLIN, Célio; LEIVAS, Paulo Gilberto Logo (Orgs.). Homossexualidade e Direitos Sexuais: reflexões a partir da decisão do STF. Porto Alegre: Sulina, 2011.

VENTURA, Miriam. Transexualidade: algumas reflexões jurídicas sobre a autonomia corporal e autodeterminação da identidade sexual. IN: RIOS, Roger Raupp (Org.). Em defesa dos direitos sexuais. Porto Alegre: Livraria do Advogado Editora, 2007. 